University of Montana

ScholarWorks at University of Montana

$4-2012$

\title{
Population-Level Compensation Impedes Biological Control of an Invasive Forb and Indirect Release of a Native Grass
}

Yvette K. Ortega

Dean E. Pearson

Lauren P. Waller

Nancy J. Sturdevant

John L. Maron

University of Montana - Missoula, john.maron@mso.umt.edu

Follow this and additional works at: https://scholarworks.umt.edu/biosci_pubs

Part of the Biology Commons

Let us know how access to this document benefits you.

\section{Recommended Citation}

Ortega, Yvette K.; Pearson, Dean E.; Waller, Lauren P.; Sturdevant, Nancy J.; and Maron, John L., "Population-Level Compensation Impedes Biological Control of an Invasive Forb and Indirect Release of a Native Grass" (2012). Biological Sciences Faculty Publications. 237.

https://scholarworks.umt.edu/biosci_pubs/237

This Article is brought to you for free and open access by the Biological Sciences at ScholarWorks at University of Montana. It has been accepted for inclusion in Biological Sciences Faculty Publications by an authorized administrator of ScholarWorks at University of Montana. For more information, please contact scholarworks@mso.umt.edu. 


\title{
Population-level compensation impedes biological control of an invasive forb and indirect release of a native grass
}

\author{
Yvette K. Ortega, ${ }^{1,4}$ Dean E. Pearson, ${ }^{1,2}$ Lauren P. Waller, ${ }^{2}$ Nancy J. Sturdevant, ${ }^{3}$ and John L. Maron ${ }^{2}$ \\ ${ }^{1}$ Rocky Mountain Research Station, USDA Forest Service, 800 East Beckwith Avenue, Missoula, Montana 59801 USA \\ ${ }^{2}$ Division of Biological Sciences, University of Montana, Missoula, Montana 59812 USA \\ ${ }^{3}$ Forest Health Protection, USDA Forest Service, P.O. Box 7669, Missoula, Montana 59807 USA
}

\begin{abstract}
The intentional introduction of specialist insect herbivores for biological control of exotic weeds provides ideal but understudied systems for evaluating important ecological concepts related to top-down control, plant compensatory responses, indirect effects, and the influence of environmental context on these processes. Centaurea stoebe (spotted knapweed) is a notorious rangeland weed that exhibited regional declines in the early 2000s, attributed to drought by some and to successful biocontrol by others. We initiated an experiment to quantify the effects of the biocontrol agent, Cyphocleonus achates, on Ce. stoebe and its interaction with a dominant native grass competitor, Pseudoroegneria spicata, under contrasting precipitation conditions. Plots containing monocultures of each plant species or equal mixtures of the two received factorial combinations of $C y$. achates herbivory (exclusion or addition) and precipitation (May-June drought or "normal," defined by the 50-year average) for three years. $\mathrm{Cy}$. achates herbivory reduced survival of adult $\mathrm{Ce}$. stoebe plants by $9 \%$ overall, but this effect was stronger under normal precipitation compared to drought conditions, and stronger in mixed-species plots compared to monocultures. Herbivory had no effect on Ce. stoebe per capita seed production or on recruitment of seedlings or juveniles. In normal-precipitation plots of mixed composition, greater adult mortality due to $C y$. achates herbivory resulted in increased recruitment of new adult Ce. stoebe. Due to this compensatory response to adult mortality, final $\mathrm{Ce}$. stoebe densities did not differ between herbivory treatments regardless of context. Experimental drought reduced adult $C e$. stoebe survival in mixed-species plots but did not impede recruitment of new adults or reduce final $\mathrm{Ce}$. stoebe densities, perhaps due to the limited duration of the treatment. Ce. stoebe strongly depressed $P$. spicata reproduction and recruitment, but these impacts were not substantively alleviated by herbivory on $\mathrm{Ce}$. stoebe. Population-level compensation by dominant plants may be an important factor inhibiting top-down effects in herbivore-driven and predator-driven cascades.
\end{abstract}

Key words: biological control; Centaurea maculosa; Centaurea stoebe; compensation; context dependence; Cyphocleonus achates; exotic plant; herbivory; indirect effects; Pseudoroegneria spicata; spotted knapweed; top-down control.

\section{INTRODUCTION}

Applied fields of ecology provide valuable testing grounds for ecological theory. Nowhere is this better illustrated than in classical biological control (henceforth "biocontrol"), which has been referred to as directed community assembly (Pearson and Callaway 2003) and is probably one of the most widespread applications of community ecology theory. Biocontrol of exotic weeds is based on the idea that top-down control by consumers may result in widespread release of community members from a strong competitive dominant: the pest weed. In essence, biocontrol is an attempt to introduce a keystone species (sensu Power et al. 1996) that initiates and maintains a favorable cascade

Manuscript received 25 April 2011; revised 5 October 2011; accepted 28 October 2011. Corresponding Editor: N. J. Sanders.

${ }^{4}$ E-mail: yortega@fs.fed.us of indirect interactions (Pearson and Callaway 2003). The keystone potential of biocontrol is qualitatively supported by a few well-documented successes, such as the suppression of St. Johnswort (Hypericum perforatum) in California (Huffaker and Kennett 1959), which illustrates both the community-wide cascading effects of the agent and the decline of the agent to relatively low abundance following weed control. Conceptually, weed biocontrol integrates topics ranging from plant-herbivore interactions, plant compensatory responses, indirect effects, and environmental conditionality, all in the context of what has proven to be a powerful but poorly studied ecological phenomenon: herbivore-initiated cascades (sensu Pringle et al. 2007).

Herbivore-initiated cascades, whether in natural or biocontrol systems, must begin with strong herbivore impacts on the host plant. A wealth of studies have shown that herbivory can suppress growth, reproduction, and survival at the individual plant level (Crawley 1989). However, individual plants commonly compen- 
sate for herbivory, and even when individuals fail to fully compensate, population-level compensation may occur. For example, seed loss can be negated by compensatory density-dependent seedling survival, and declines in adult abundance can be countered by enhanced performance of surviving individuals released from intraspecific competition (Crawley 1989, Garren and Strauss 2009, Swope and Parker 2010). While the number of studies that quantify herbivore impacts at the population level are beginning to increase, our understanding of the strength of these processes is still poorly developed (Maron and Crone 2006). More surprising is the fact that biocontrol studies rarely measure population-level impacts of herbivory despite the importance of such data for determining biocontrol efficacy (Carson et al. 2008). Thus, although negative impacts of biocontrol agents on target plant performance are often assumed to be a measure of biocontrol success (Carson et al. 2008), it is increasingly clear that compensation at the population level can strongly decouple reductions in individual performance from suppression of weed abundance (Myers et al. 1990, Garren and Strauss 2009, Swope and Parker 2010).

Biotic and abiotic conditions, i.e., environmental context, can greatly influence both direct and indirect effects of herbivory. In natural systems, one consistent pattern that emerges from studies examining population-level impacts of herbivores on plants is that results strongly hinge on environmental context (Maron and Crone 2006). Contingency is also a hallmark of biocontrol (Syrett et al. 2000, Shea et al. 2005). Not only are the direct effects of herbivores on plants context dependent, so too can be the cascading indirect effects (Pringle et al. 2007). Though many biotic and abiotic factors have been shown to attenuate indirect effects and undermine trophic cascades (Polis et al. 2000, Borer et al. 2005, Mooney et al. 2010), little work has addressed their influence on herbivore-initiated cascades (Pringle et al. 2007). In the context of biocontrol, the hope is that control agents initiate density-mediated cascades wherein herbivory suppresses weed populations sufficiently to allow release of subordinate competitors. Yet, how much suppression is enough and how strongly do environmental factors condition these outcomes? The biocontrol literature refers to an "ecological threshold" for suppression (e.g., van Driesche and Bellows 1996), but break points associated with indirect cascading effects are poorly understood in both biocontrol and natural systems. In short, many factors are known to facilitate or attenuate indirect effects, but we still lack the knowledge to predict when consumer vs. resource control should prevail (Gruner et al. 2008, MacDougall et al. 2010). Advancing understanding of cascading interactions in both biocontrol and natural systems requires comprehensive experiments that examine herbivory, plant compensation, and indirect effects at individual, population, and community scales, while also manipulating background environmental conditions. Despite the enormous potential that biocontrol systems offer for examining these issues, ecologists have been slow to capitalize on this opportunity.

We used the exotic perennial forb, Centaurea stoebe (spotted knapweed; Asteraceae), and its biocontrol agent, Cyphocleonus achates (Coleoptera), as a model system to examine the direct and indirect effects of biocontrol herbivory under differing environmental conditions. Ce. stoebe is a notorious weed that exhibited regional population declines of $>60 \%$ in the early 2000s, attributed to drought by some (Pearson and Callaway 2006, Pearson and Fletcher 2008, Ortega and Pearson 2011) and to successful biocontrol by others (Story et al. 2006, 2008). A plausible explanation for these conflicting conclusions could be that top-down effects of biocontrol agents on Ce. stoebe increase under drought stress. Here we report results from an experiment in which we quantified the biocontrol agent's effects on $\mathrm{Ce}$. stoebe at the individual and population levels, and evaluated how effects of herbivory translated to indirect effects on a dominant native grass under contrasting precipitation regimes. We hypothesized that the direct and indirect effects of biocontrol herbivory would be greater under drought compared with average precipitation conditions.

\section{Methods}

To examine context-dependent impacts of a biocontrol agent on Ce. stoebe, and to determine how they might indirectly influence native plant species, we conducted an experiment at Diettart Experimental Gardens in Missoula, Montana, USA. For the focal native species, we chose the perennial bunchgrass Pseudoroegneria spicata (bluebunch wheatgrass; Poaceae) because it dominates native grasslands of the region and its abundance is strongly reduced by $\mathrm{Ce}$. stoebe (Ortega and Pearson 2005). We created $1 \times 1 \mathrm{~m}$ plots planted with $C e$. stoebe only, P. spicata only, or $C e$. stoebe and $P$. spicata. Each of these composition treatments was factorially crossed with a $C y$. achates herbivory treatment $( \pm$ herbivore) and a precipitation treatment ( \pm drought) with one exception: the herbivory treatment was not applied to $P$. spicata monocultures because $C y$. achates does not attack this species. This design yielded 10 treatment combinations, which were randomly assigned to plots arranged in a $2 \times 5$ pattern within 15 replicate blocks.

We prepared the site by mowing an existing Ce. stoebe infestation, tilling the soil, watering daily to flush the seed bank, and then applying a non-selective, lowpersistence herbicide (Roundup; Monsanto, St. Louis, Missouri, USA) in October 2005 and April 2006. We grew $C e$. stoebe and $P$. spicata from locally collected seed in a greenhouse for three months. In May 2006, we transplanted 36 plants spaced $20 \mathrm{~cm}$ apart into a $6 \times 6$ arrangement within each plot. Mixed-species plots were composed of 18 Ce. stoebe and 18 P. spicata plants arranged in an alternating pattern. We watered plots every 48 hours and replaced dead plants during the first season only. All plots were weeded periodically to 
maintain species composition. Experimental treatments were initiated in 2007, and all sampling was conducted in 2007-2009 except as noted. We sampled only the inner 16 plants and the corresponding $0.8 \times 0.8 \mathrm{~m}$ portion of the plot to avoid edge effects, and all stems from edge plants were clipped before seed dispersal. Two plots with high initial mortality ( $>5$ of 16 focal plants) were excluded from analyses.

The specialist weevil, Cyphocleonus achates, was introduced for Ce. stoebe control in the early 1990s and is commonly credited for causing declines in its host (Story et al. 2006). Adult Cy. achates emerge midsummer to breed and lay eggs, and larvae overwinter within Ce. stoebe roots. On 14 August 2007, 16 locally collected adult $C y$. achates were added to each herbivore-addition plot. This release density is comparable to those used in other studies reporting impacts of $C y$. achates on $\mathrm{Ce}$. stoebe (Corn et al. 2006, 2007). Because Cy. achates is virtually flightless, we were able to control access in each plot using a $30.5-\mathrm{cm}$ aluminum barrier buried $10 \mathrm{~cm}$ deep and $45 \mathrm{~cm}$ from the plot edge (Story et al. 1996). Barriers were folded at the top to form a 4-cm lip hindering $C y$. achates passage. We conducted twominute visual searches for adult $C y$. achates from late August to early September, 2008 ( $n=1$ survey) and 2009 ( $n=5$ surveys). This method greatly underestimates $C y$. achates density and is sensitive to weather conditions (Clark et al. 2001). Therefore, these data were only used to compare abundance among treatments within each year. Other Ce. stoebe biocontrol agents common at the site were the gallflies Urophora affinis and $U$. quadrifaciata, and the weevils Larinus minutus and L. obtusus, all of which attack Ce. stoebe capitula (Story et al. 2006). In addition, the root-boring moth Agapeta zoegana was present but rare based on visual observations of adults (Clark et al. 2001). Because these biocontrol agents could not be excluded from plots without impacting plants, our experiment tested for effects of $C y$. achates in the presence of these agents.

In May and June of each year, we reduced water inputs in drought-treatment plots to $20 \%$ of average precipitation $(0.9 \mathrm{~cm}$ and $1.0 \mathrm{~cm}$ for May and June, respectively), based on levels recorded from 1957-2006 in Missoula, Montana. This level approximated drought conditions observed in 2000 and 2001, coincident with steep declines in Ce. stoebe in some western Montana grasslands (e.g., Pearson and Fletcher 2008). All precipitation was excluded from drought plots using motorized rain covers made from vinyl blinds mounted on PVC frames measuring $140 \mathrm{~cm}$ on each side. Covers were only deployed during rain events, except at night if the chance of rain was $>30 \%$. We watered drought plots bimonthly to attain target inputs. For the non-drought treatment (hereafter "normal"), and during non-treatment months from July to September, ambient precipitation was supplemented with watering bimonthly as necessary to attain average precipitation levels. We continuously monitored ambient precipitation levels with a Rain Logger (Rainwise, Bar Harbor, Maine,
USA), and measured soil moisture (volumetric water content) at a depth of $12 \mathrm{~cm}$ monthly, 2008-2009, using a handheld probe (Field Scout TDR-100; Spectrum Technologies, Plainfield, Illinois, USA).

We uniquely marked all transplants and assessed their survival in May and September. In May, we also measured the diameter of each plant along two perpendicular axes. In August, we counted flowering stems and marked and counted new adults (flowering plants) that recruited into the population. When seeds matured, we collected one randomly selected flowering stem for eight plants per species per plot, and estimated the number of seeds per $\mathrm{Ce}$. stoebe stem by determining the number of seed heads per stem and the mean number of seeds per seed head, calculated from a random sample of 20 seed heads. For the latter, we also counted Urophora larvae and recorded the presence of Larinus emergence holes. We germinated seeds from the first 10 selected $C e$. stoebe seed heads per stem and from all collected $P$. spicata stems on wet filter paper at $21^{\circ} \mathrm{C}$ under ambient light. Seeds not germinated after seven days were considered nonviable. Per capita production of viable seeds per plot was calculated by multiplying estimated numbers of stems per live plant and seeds per stem by the plot-level germination rate.

In spring 2007, we removed all Ce. stoebe seedlings in plots because they originated from the residual seed bank. In the fall, we counted seedlings of each species at the peak of emergence within a centrally located $0.25 \times$ $0.25 \mathrm{~m}$ subplot. In fall 2007, few Ce. stoebe seedlings $(<3$ per subplot) were found in $P$. spicata monocultures, indicating that the pre-experimental seed bank had been largely exhausted. Seedling counts were repeated in spring for Ce. stoebe, which germinates twice per year. Coincident with seedling sampling, we also counted juvenile plants, defined as nonreproductive individuals originating in a prior season.

\section{Statistical analyses}

We used generalized linear mixed models (PROC GLIMMIX, SAS version 9.2; SAS Institute 2009) to test for effects of herbivory, precipitation, and species composition on Ce. stoebe and P. spicata, respectively. We present results for the final sampling year only since results were comparable among years. Block was treated as a random factor in all models. Models for Ce. stoebe included all three experimental factors and their interactions as fixed factors. For $P$. spicata models, because the herbivory treatment was not applied to grass-only plots, we combined species composition and herbivory treatments into one factor, i.e., $P$. spicata only; P. spicata with Ce. stoebe, herbivore added; and $P$. spicata with $C e$. stoebe, herbivore excluded. To test for post hoc differences among treatment means, we used multiple comparisons adjusted for the number of comparisons. We present least squares means and SEs throughout. For brevity, we combine statistics from multiple nonsignificant tests by presenting maximum $F$ 
values and minimum $P$ values. Statistics for individual tests are available in Appendices A-C.

To examine effects on mean diameter per live plant, we included plot within block as a random factor. There were small pretreatment differences in mean size of $\mathrm{Ce}$. stoebe plants: mean diameter in herbivore-addition relative to herbivore-exclusion plots tended to be smaller in drought plots $(26.5 \pm 0.78 \mathrm{~cm}$ vs. $27.6 \pm 0.8 \mathrm{~cm}$ [mean $\pm \mathrm{SE}])$ but larger in normal-precipitation plots $(27.9 \pm$ $0.78 \mathrm{~cm}$ vs. $\left.26.0 \pm 0.8 \mathrm{~cm} ; F_{1,98}=5.4, P=0.023\right)$. Hence, we included a diameter covariate in Ce. stoebe models, scaled to reflect random variation within each composition treatment (pretreatment diameter divided by the mean for each composition type).

We tested for effects on per capita survival of the original cohort across the three years of the study (alive or dead as of fall 2009) using a binomial distribution, with plot within block also included in the model as a random factor. Effects on per capita reproductive measures and raw numbers of seedlings, juveniles, and new adults per plot, respectively, were assessed using a negative binomial or Poisson (modified for overdispersion) distribution, depending on which provided the best fit (SAS Institute 2009). We tested for differences in the number of $C y$. achates adults detected per plot (averaged across all surveys for 2009) using a full factor model with a negative binomial distribution and block as a random factor. A parallel model with a binomial distribution was used to test for differences in occurrence of Larinus and Urophora within Ce. stoebe seed heads, with plot within block also included as a random factor. To test for differences in soil moisture among treatments (herbivory and species composition factors combined), we used a repeated measures model with a normal distribution.

\section{RESULTS}

Our herbivory treatment effectively controlled access of the biocontrol agent, $C y$. achates, to plots containing its host, Ce. stoebe. In 2008, a year after release, we observed $4.0 \pm 0.49$ adult $C y$. achates per herbivoreaddition plot compared to $0.02 \pm 0.017$ adults per herbivore-exclusion plot (mean $\pm \mathrm{SE} ; F_{1,114}=28.9, P<$ $0.0001)$. In 2009, we observed $2.5 \pm 0.02$ adults per herbivore-addition plot compared to $0.1 \pm 0.05$ adults per herbivore-exclusion plot $\left(F_{1,100}=49.4, P<0.0001\right)$. The number of $C y$. achates per plot did not differ by species composition or precipitation treatment in either year $\left(F_{1,100-114}<1.5, P>0.23\right)$. Occurrence of Larinus and Urophora biocontrol agents within Ce. stoebe seed heads did not differ significantly among treatments in any year $\left(F_{1,95-109}<2.8, P>0.097\right)$. Urophora occurred in $65-91 \%$ of seed heads across years $(2.9 \pm 0.07-4.0 \pm$ 0.09 larvae/seed head), while Larinus occurred in 18$37 \%$ of seed heads (always one per seed head), with 88 $95 \%$ of seed heads containing at least one of these biocontrol agents.

The drought treatment succeeded in reducing soil moisture during May and June. (For 2008: $F_{1,70}=307.1$,
$P<0.0001$; drought, $4.9 \pm 0.21 \%$, normal, $9.6 \pm 0.21 \%$. For 2009: $F_{1,84}=203.3, P<0.0001$; drought, $3.9 \pm$ $0.2 \%$, normal, $8.0 \pm 0.2 \%$ ). During the remaining months of the growing season, there was no difference in soil moisture between drought and normal plots across years $\left(F_{1,103}<0.5, P>0.5\right)$. In no case did the precipitation treatment interact with the herbivory or species composition treatments $\left(F_{2,70-95}<0.8, P>0.4\right)$.

\section{Effects on Ce. stoebe}

The diameter of the exotic forb, Ce. stoebe, was larger in mixed-species plots containing the grass $P$. spicata $(21.8 \pm 0.76 \mathrm{~cm})$ than in Ce. stoebe monocultures $(19.1$ $\left.\pm 0.71 \mathrm{~cm} ; F_{1,98}=19.4, P<0.0001\right)$, and larger in drought $(21.1 \pm 0.73 \mathrm{~cm})$ compared to normal plots $\left(19.7 \pm 0.73 \mathrm{~cm} ; F_{1,98}=5.8, P=0.018\right)$. Remaining factors and their interactions were not significant $\left(F_{1,98}\right.$ $<1.4, P>0.24)$.

Overall, survival of $C e$. stoebe adults was lower in plots with the biocontrol agent, $C y$. achates, compared to plots where it was excluded $\left(F_{1,100}=5.7, P=0.019\right)$, but the strength of this effect varied between precipitation and species composition treatments (Fig. 1). Herbivory reduced $\mathrm{Ce}$. stoebe survival more markedly in normal-precipitation compared to drought plots (herbivory $\times$ precipitation: $F_{1,102}=6.6, P=0.012$ ), and in mixed-species plots compared to monocultures (herbivory $\times$ composition: $F_{1,101}=6.7, P=0.011$ ). Overall, herbivory reduced mean survival by nearly $30 \%$ in plots with normal precipitation and mixed composition, but by $<10 \%$ in remaining plot types (Fig. 1), although the three-way interaction among treatment factors was not significant $\left(F_{1,100}=0.7, P=0.41\right)$. Ce. stoebe survival did not differ significantly between composition $\left(F_{1,100}=3.3, P=0.073\right)$ or precipitation treatments $\left(F_{1,101}=0.3, P=0.6\right)$, but these factors interacted $\left(F_{1,100}=4.3, P=0.041\right)$. Specifically, drought tended to reduce survival in mixed-species plots, particularly in the herbivore-exclusion treatment, but increase survival in monocultures (Fig. 1).

$C y$. achates herbivory did not significantly affect production of $C e$. stoebe flowering stems or viable seeds $\left(F_{1,95}<1.3, P>0.26\right)$, nor did herbivory interact with other factors $\left(F_{1,95}<1.7, P>0.21\right.$; Fig. 2$)$. Mean numbers of flowering stems and viable seeds per $C e$. stoebe were $>30 \%$ higher in mixed-species plots relative to monocultures $\left(F_{1,95}>7.9, P<0.007\right)$. Precipitation did not significantly affect stem or seed production $\left(F_{1,95}\right.$ $<2.7, P>0.1)$, or interact with species composition $\left(F_{1,95}<3.0, P \geq 0.09\right)$.

Across seasons, $C y$. achates herbivory did not significantly affect the density of $\mathrm{Ce}$. stoebe seedlings or juveniles $\left(F_{1,95}<2.3, P>0.14\right)$, nor interact with other factors (two-way interactions: $F_{1,95}<1.5, P>$ 0.22; three-way: $\left.F_{1,95} \leq 3.6, P \geq 0.061\right)$. Similarly, seedling and juvenile densities did not differ significantly between composition treatments $\left(F_{1,95}<2.6, P>0.1\right)$. Spring seedling densities were lower in drought compared to normal plots $\left(3.0 \pm 0.54\right.$ individuals $/ 0.06 \mathrm{~m}^{2}$ 
vs. $4.4 \pm 0.76$ individuals $/ 0.06 \mathrm{~m}^{2} ; F_{1,95}=4.1, P=$ $0.046)$. However, spring juvenile densities were higher in drought compared to normal plots $(22.2 \pm 3.19$ individuals $/ 0.06 \mathrm{~m}^{2}$ vs. $18.0 \pm 2.66$ individuals $/ 0.06$ $\left.\mathrm{m}^{2} ; F_{1,95}=4.1, P=0.046\right)$. Moreover, fall densities of seedlings $\left(0.6 \pm 0.21\right.$ individuals $\left./ 0.06 \mathrm{~m}^{2}\right)$ and juveniles $\left(16.6 \pm 2.4\right.$ individuals $\left./ 0.06 \mathrm{~m}^{2}\right)$ did not differ between precipitation treatments $\left(F_{1,95}<0.7, P>0.44\right)$. Across seasons, the precipitation $\times$ species composition interaction was not significant for either seedlings or juveniles $\left(F_{1,95} \leq 2.8, P \geq 0.099\right)$.

A subset of $\mathrm{Ce}$. stoebe juveniles transitioned to new adults in 2009, compensating for mortality of the original cohort. Although the density of new adults was not affected by $C y$. achates herbivory overall $\left(F_{1,95}\right.$ $=0.08, P=0.78)$, effects of this treatment varied by environmental context (Fig. 3). Herbivory promoted recruitment of new adults, but only under normal precipitation conditions (herbivory $\times$ precipitation: $\left.F_{1,95}=6.1, P=0.015\right)$ and specifically in mixed-species plots containing the grass $P$. spicata (herbivory $\times$ precipitation $\times$ composition: $\left.F_{1,95}=4.3, P=0.04\right)$. In plots with normal precipitation and mixed composition, where herbivory caused the strongest reduction in survival of the original cohort, mean density of new adults was six-fold higher in the herbivore addition vs. exclusion treatment (post hoc test: $t_{95}=2.7, P=0.038$ ). In remaining cases, differences between herbivory treatments were not significant (post hoc tests: $t_{95}<$ $1.8, P>0.32$ ). Density of adult recruits did not differ significantly between composition $\left(F_{1,95}=3.3, P=\right.$ $0.074)$ or precipitation treatments $\left(F_{1,95}=0.1, P=0.74\right)$, nor did these factors interact $\left(F_{1,95}=0.8, P=0.39\right)$.

Because recruitment compensated for mortality of the original cohort, total densities of $\mathrm{Ce}$. stoebe adults at the end of the experiment (fall 2009) paralleled those at the onset of the experiment, with $16 \pm 0.8$ plants in monocultures and $8 \pm 0.6$ plants in mixed-species plots. Final densities of $\mathrm{Ce}$. stoebe did not differ between herbivory or precipitation treatments $\left(F_{1,109}<1.1, P>\right.$ 0.31 , nor did these factors interact with species composition $\left(F_{1,109}<2.5, P>0.12\right)$.

\section{Effects on P. spicata}

The diameter of the native grass, $P$. spicata, was larger in monoculture plots $(4.6 \pm 0.17 \mathrm{~cm})$ compared to mixed $P$. spicata-Ce. stoebe plots with the herbivore either added $(3.2 \pm 0.18 \mathrm{~cm})$ or excluded $(3.1 \pm 0.18 \mathrm{~cm}$; post hoc tests: $\left.t_{63}>7.8, P<0.0001\right)$. Differences in diameter between herbivory (post hoc test: $t_{77}=0.5, P>0.99$ ) and precipitation treatments $\left(F_{1,68}=3.0, P=0.088\right)$ were not significant, nor did experimental factors interact $\left(F_{2,67}=\right.$ 1.6, $P=0.23)$. Survival of original $P$. spicata plants was $93 \%$ ( $n=896$ of 960 plants), and did not differ significantly between composition, herbivory $\left(F_{2,90}=\right.$ $1.1, P=0.34)$ or precipitation treatments $\left(F_{1,101}=2.4\right.$, $P=0.13)$, nor did these factors have an interactive effect on $P$. spicata survival $\left(F_{2,91}=1.7, P=0.19\right)$.

$C$ e. stoebe negatively impacted $P$. spicata per capita reproductive measures. $P$. spicata stem and seed pro-



FIg. 1. Effect of addition vs. exclusion of the biocontrol herbivore, Cyphocleonus achates, on survival (mean $+\mathrm{SE}$ ) of adult Centaurea stoebe plants from 2007-2009 under normal precipitation (50-year average) and drought conditions in common-garden plots containing either the native grass, Pseudoroegneria spicata, or Ce. stoebe only. Herbivory reduced survival, particularly in normal-precipitation and mixed-species plots, while drought tended to reduce survival in mixed-species plots only, particularly in the absence of herbivory (see Results).

duction were approximately two-fold higher in monocultures relative to mixed-species plots whether the herbivore was added (post hoc tests: $t_{70} \geq 2.6, P \leq$ 0.035 ) or excluded (post hoc tests: $t_{70}>4.7, P<0.0001$; Fig. 4A and B). Although there was a trend toward increased $P$. spicata reproduction in herbivore-addition vs. herbivore-exclusion plots, neither stem production (post hoc test: $t_{70}=2.2, P=0.09$ ) nor viable seed production (post hoc test: $t_{70}=1.8, P=0.21$ ) differed significantly between herbivory treatments. The precipitation treatment did not significantly affect $P$. spicata reproductive measures $\left(F_{1,70}<1.1, P>0.31\right)$, or interact with herbivory or composition treatments $\left(F_{2,70}\right.$ $<0.4, P>0.76)$.

Ce. stoebe strongly reduced density of young $P$. spicata plants, and these impacts were not alleviated by $C y$. achates herbivory. Mean seedling and juvenile densities were more than threefold higher in pure $P$. spicata plots relative to mixed-species plots with the herbivore either added or excluded (post hoc tests: $t_{70}>$ 5.2, $P<0.0001$; Fig. 4C and D). Neither seedling density nor juvenile density differed significantly be- 

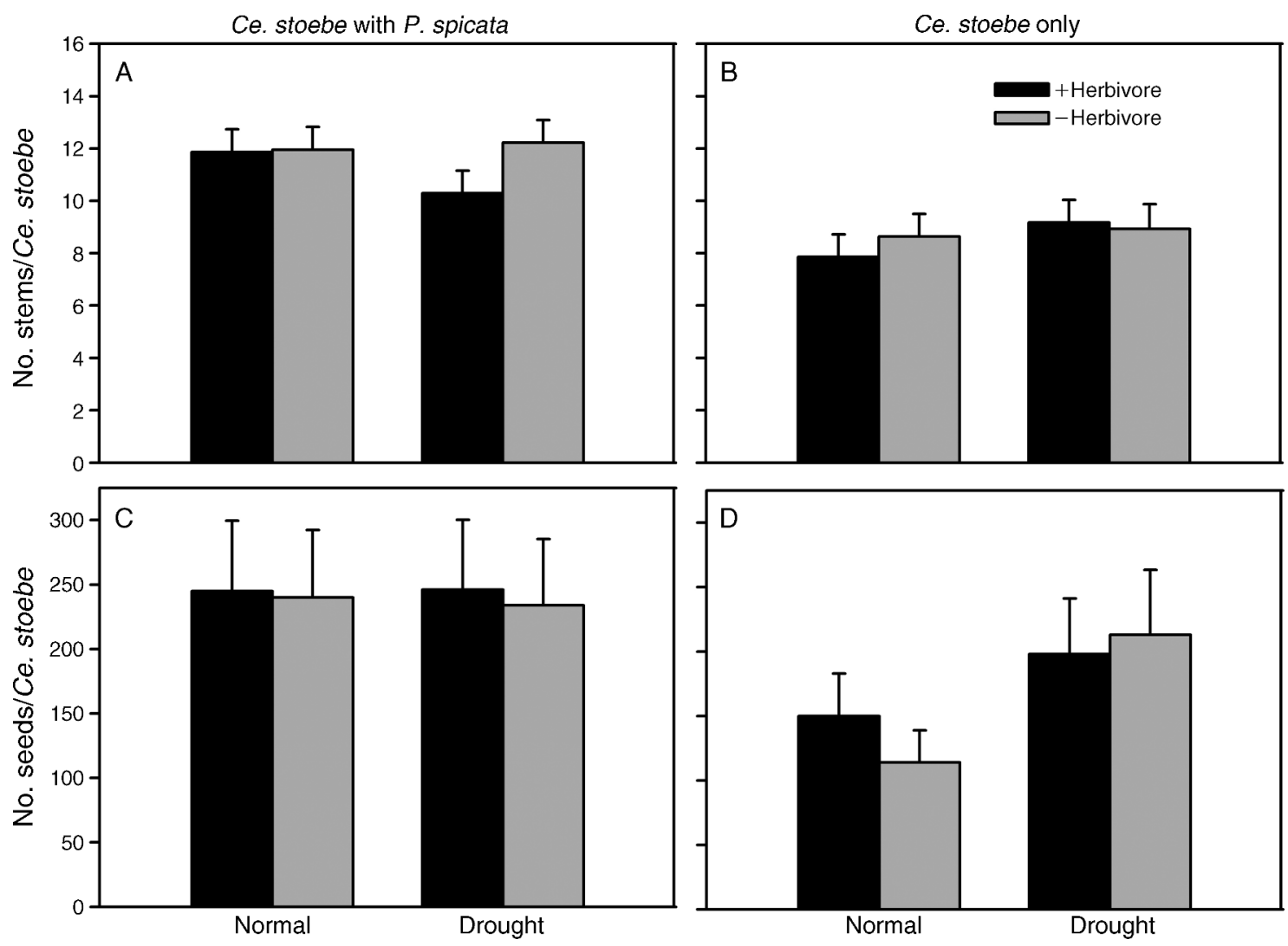

FIG. 2. Effect of addition vs. exclusion of the biocontrol herbivore, Cyphocleonus achates, on numbers (mean $+\mathrm{SE})$ of $(\mathrm{A}, \mathrm{B})$ flowering stems and (C, D) viable seeds per Centaurea stoebe plant under normal precipitation (50-year average) and drought conditions in common-garden plots containing either the native grass, Pseudoroegneria spicata, or Ce. stoebe only. Stem and seed production were greater in mixed-species plots than in monocultures (see Results).

tween herbivore-addition and exclusion plots (post hoc tests: $\left.t_{70}<1.8, P>0.25\right)$. Similarly, the precipitation treatment did not significantly affect density of $P$. spicata seedlings or juveniles $\left(F_{1,70}<3.0, P>0.094\right)$, or interact with herbivory or composition treatments $\left(F_{2,70}<1.6, P>0.23\right)$. No young $P$. spicata transitioned to adults during the experiment.

Adult $P$. spicata densities at the end of the experiment were $15 \pm 0.2$ plants in monoculture plots and $7 \pm 0.2$ plants in mixed-species plots. Final densities did not differ between herbivory (post hoc test: $t_{70}=0.6, P>$ $0.99)$ or precipitation treatments $\left(F_{1,70}=1.5, P=0.22\right)$, nor did these factors interact with species composition $\left(F_{2,70}=1.2, P=0.32\right)$.

\section{Discussion}

The objective in weed biocontrol is to suppress target weed abundance below the economic or ecological threshold of impact (van Driesche and Bellows 1996). In other words, a primary goal of biocontrol is to reduce target species to the point where desirable species may increase. Yet experimental studies examining the full cycle of biocontrol effects, from impacts on target-weed performance measures to population-level impacts and finally to effects on other plant species, are remarkably rare. In fact, we know of no study that has experimentally examined this entire chain of effects, from the individual to the community, while also examining how these effects might be modified by environmental context. As a result, our ability to predict when and where biocontrol might work, and what factors might modify its success, is extremely limited. In examining these questions for the notorious weed, Ce. stoebe, and a biocontrol agent purported to control this weed, we found that herbivory caused mortality of host plants and that this outcome was conditioned by biotic and abiotic context. However, due to strong population-level compensation, individual mortality was insufficient in any context to reduce target weed populations, and hence, failed to release the native community dominant from impacts of the weed.

Compensatory recruitment has long been recognized as a mechanism that can reduce the population-level impacts of herbivores on plants (Crawley 1989), but how often it occurs, and under what conditions, remains unclear in both natural and biocontrol settings (Maron and Crone 2006). Thus, while there are many reports of biocontrol agents reducing weed performance, including survival (e.g., Syrett et al. 2000, Carson et al. 2008), we know surprisingly little about how often these reduc- 
tions in individual plant performance result in meaningful weed suppression (Shea et al. 2005, Garren and Strauss 2009, Swope and Parker 2010). In our study, reduction of adult survival by herbivores promoted recruitment of new adults by hastening the transition of juveniles to adults, presumably due to competitive release. Indeed, the density of new Ce. stoebe adults was negatively correlated with the density of original adults in both mixed-species plots $\left(F_{1,41}=18.5, P<\right.$ $0.0001)$ and monocultures $\left(F_{1,41}=28.5, P<0.0001\right)$, but it was not correlated with the density of juveniles measured in the preceding spring $\left(F_{1,4}<1.6, P>0.22\right)$. Recent studies of the weed, Centaurea solstitialis (Garren and Strauss 2009, Swope and Parker 2010), similarly documented population-level compensation in response to biocontrol herbivory, though the mechanism identified was different. These studies found that seed loss caused by biocontrol agents was negated by enhanced seed production of individuals in the next generation. Such population-level compensation not only thwarts long-term suppression of the target weed, but also eliminates any potential for beneficial indirect effects that might release co-occurring species from weed impacts. More generally, population-level compensation by dominant plants could be an important factor impeding herbivore-driven cascades, as well as traditional predator-driven trophic cascades. Post-release studies of biocontrol efficacy that examine populationand community-level responses could contribute greatly to understandings of top-down control and cascading indirect effects.

We found that biotic context was important in determining the herbivore's impact on survival of the target weed. Herbivory caused a significant increase in mortality of the weed, Ce. stoebe, but only in mixedspecies plots containing a native competitor. This result parallels other studies showing additive or synergistic effects of interspecific competition and herbivory on plants (McEvoy and Coombs 1999, Sheppard et al. 2001). We also found that abiotic context conditioned herbivore impacts. In mixed-species plots, negative effects of drought on Ce. stoebe survival were similar in magnitude to negative effects of the biocontrol agent, but the latter were only apparent in the absence of drought. Although we expected that drought stress would increase susceptibility of $\mathrm{Ce}$. stoebe to the biocontrol agent, drought appeared to negate herbivore impacts. This outcome could have arisen via several potential mechanisms. Drought could have had a direct negative effect on $C y$. achates or an indirect negative effect, e.g., if drought-stressed plants became poor resources for the herbivore. Alternatively, the lack of herbivore effects under drought conditions could have occurred if the same plants susceptible to herbivore-induced mortality were also susceptible to drought-induced mortality, i.e., effects were fully compensatory. Because we did not see differences in prevalence of the biocontrol agent among treatments, the latter mechanism seems most likely. However, drought could have had more subtle effects on

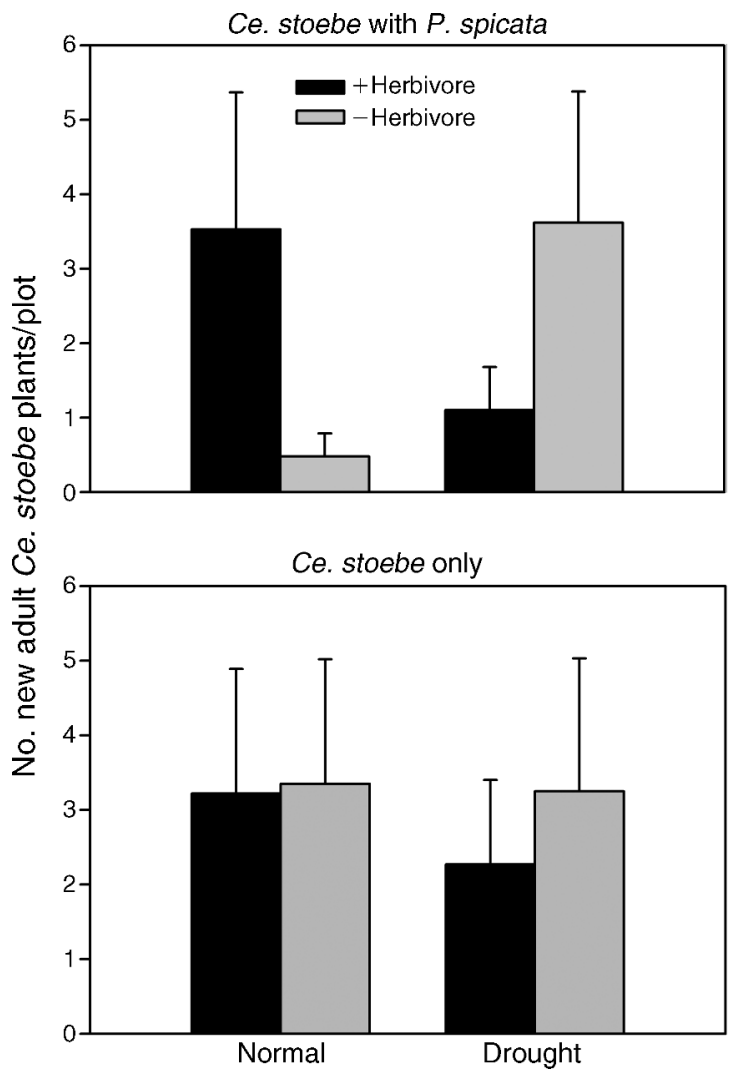

FIG. 3. Effect of addition vs. exclusion of the herbivore, Cyphocleonus achates, on recruitment of adult Centaurea stoebe plants (mean $+\mathrm{SE}$ ) under normal precipitation (50-year average) and drought conditions in common-garden plots containing either the native grass, Pseudoroegneria spicata, or Ce. stoebe only. Herbivory led to increased recruitment in mixed-species plots with normal precipitation (see Results).

$C y$. achates by altering feeding behavior. In any case, final densities of Ce. stoebe adults in all treatments were equivalent to initial densities due to strong compensatory recruitment. Context dependence is recognized as a ubiquitous determinant of interaction outcomes in nature, and has been a bane to biocontrol in that virtually all biocontrol successes are spatially or temporally limited by biotic or abiotic conditions (e.g., Syrett et al. 2000, Shea et al. 2005). Studies of future biocontrol releases carefully designed to address environmental context could greatly expand our understanding of the roles of biotic and abiotic factors in determining resource vs. consumer control and indirect effects in general.

The strongest interaction that we observed was the negative impact of $\mathrm{Ce}$. stoebe on the dominant native grass, $P$. spicata. Ce. stoebe suppressed $P$. spicata growth, reproduction, and recruitment of young cohorts by as much as $80 \%$ across all conditions. Meanwhile, Ce. stoebe plants were larger and produced more stems and viable seeds when adjacent to $P$. spicata plants compared to conspecifics, suggesting that the weed faced weaker interspecific than intraspecific competition. Notably, competitive dominance of $\mathrm{Ce}$. stoebe was not substan- 

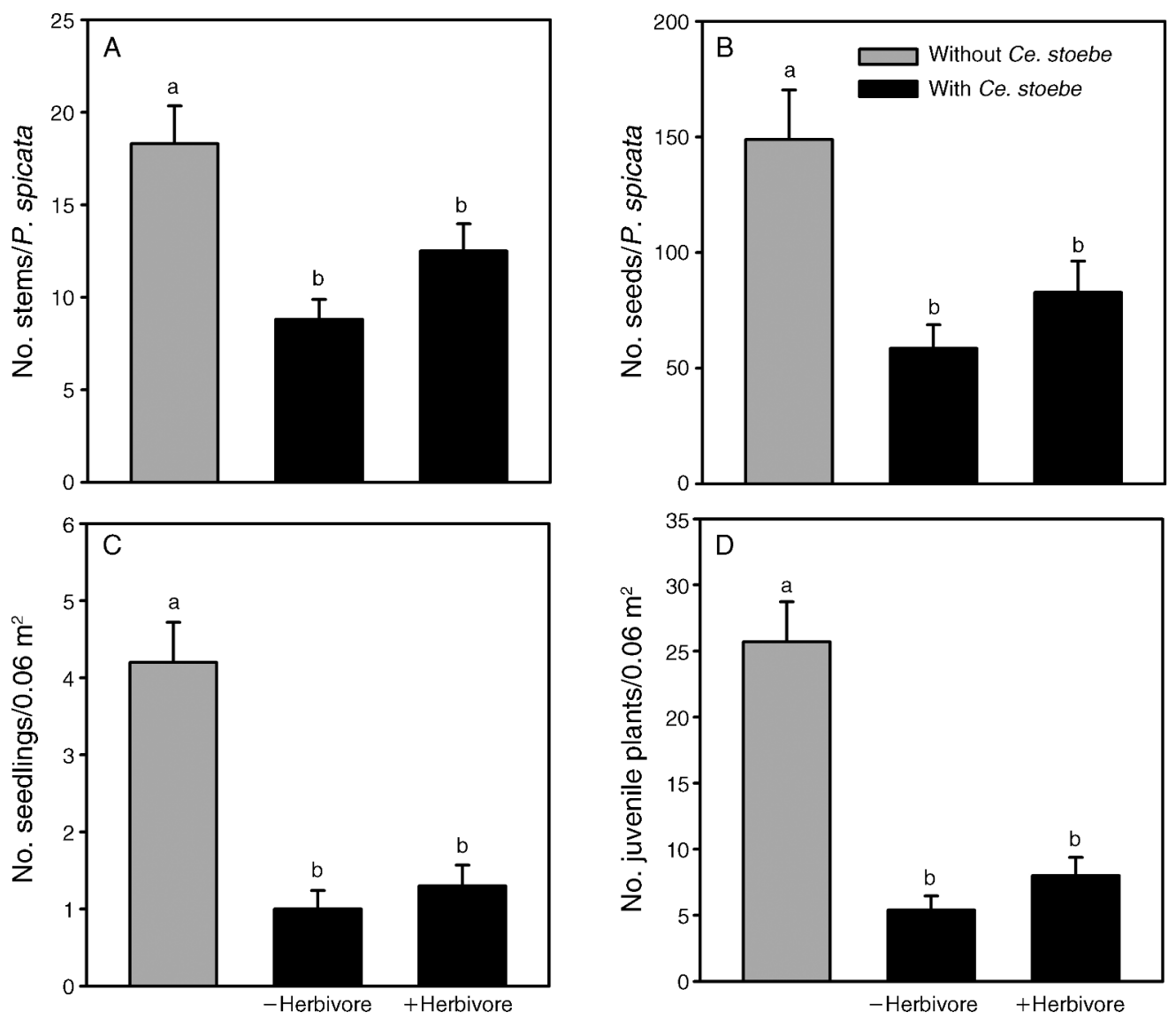

FIG. 4. Numbers (mean + SE) of (A) flowering stems, (B) viable seeds, (C) seedlings, and (D) juveniles produced by the native grass Pseudoroegneria spicata in common-garden plots without the exotic forb Centaurea stoebe, or with Ce. stoebe and either the addition or exclusion of the biocontrol herbivore Cyphocleonus achates. Different letters above bars indicate significant differences between treatments $(P<0.05$, post hoc tests). Drought conditions did not affect results $(P>0.7)$, so data are summarized across these treatments. Ce. stoebe reduced $P$. spicata reproduction and recruitment, but herbivory on $C e$. stoebe did not significantly alleviate these impacts (see Results).

tively weakened by herbivory. Although there was a trend toward improved reproduction of $P$. spicata in the herbivory treatment, this trend was not significant and did not translate to improved recruitment. Previous field experiments reported that Ce. stoebe's competitive dominance over several native grass species was actually strengthened by the root-feeding biocontrol agent, Agapeta zoegena (Callaway et al. 1999, Thelen et al. 2005). However, few studies have rigorously examined the effects of biocontrol herbivory on the competitive strength of weeds. Ce. stoebe exhibits strong competitive dominance over numerous native grasses and forbs (Callaway et al. 1999, Thelen et al. 2005, Maron and Marler 2008). Hence, the level of biocontrol impact required to release natives from competition with $\mathrm{Ce}$. stoebe and other dominant weeds may often be very high. The question arises then, just how great must herbivore impacts be to release natives from such strong competitive dominance? Experiments manipulating levels of simulated herbivory could be used as a general assay for determining how much impact it would take to cause population declines sufficient to release native competitors.
So how do our results relate to prior studies of $\mathrm{Ce}$. stoebe biocontrol? Several field studies have reported declines in Ce. stoebe and attributed these declines to successful biocontrol (Jacobs et al. 2006, Story et al. 2006, 2008, Seastedt et al. 2007). However, these studies failed to include trend data from control sites (where the agents were absent) to account for extraneous factors such as drought. Meanwhile, experimental studies concluding that $C y$. achates is capable of controlling Ce. stoebe have shown decrements in $\mathrm{Ce}$. stoebe performance similar to those we observed (Corn et al. 2006, 2007, Knochel et al. 2010; see also Knochel and Seastedt 2010), but as we clearly show, such effects do not necessarily translate to reduced abundance of $\mathrm{Ce}$. stoebe, or to the release of native competitors. Initial densities of the biocontrol agent $C y$. achates in our study were comparable to those in other experiments (e.g., Corn et al. 2006, 2007), and abundance estimates in subsequent years were more than five times higher than those obtained at field sites where the agent was reported to be successful (Story et al. 2006). Performance measures for $\mathrm{Ce}$. stoebe were also comparable to those 
reported for field populations in Montana (e.g., Jacobs et al. 2006, Story et al. 2008). Hence, our experimental conditions were representative of natural conditions and provide the most comprehensive examination of this system to date, yet we failed to find evidence for herbivore control of $\mathrm{Ce}$. stoebe populations. It is certainly possible that biocontrol agents may have stronger effects on $\mathrm{Ce}$. stoebe under different circumstances, particularly if agents reach unusually high numbers or plant competition is particularly strong, such as when other strong invaders are present (Jacobs et al. 2006). However, we found that $C$ e. stoebe can compensate at the population level for individual mortality at relatively high $C y$. achates abundance, even with an experimentally depleted seed bank and under drought conditions. These results suggest that Ce. stoebe may be particularly insensitive to biocontrol, echoing findings for C. solstitialis (Garren and Strauss 2009, Swope and Parker 2010).

Ce. stoebe populations did not succumb to drought in our experiment. A plausible explanation for this may be the limited duration of our drought treatment, which was restricted to two months in spring. In contrast, the severe drought conditions associated with record-setting wildfires and Ce. stoebe declines in Montana in the early 2000 s, particularly in 2000, extended over the fourmonth growing season, when precipitation was $50 \%$ below the 50 -year average of $5.7 \mathrm{~cm}$ in Missoula. Also, our drought treatment did not control for factors such as temperature and humidity that contribute to drought stress. Hence, drought may still offer the most parsimonious explanation for observed declines of Ce. stoebe across our region, particularly given the absence of biocontrol agents such as $C y$. achates at most sites where declines occurred (e.g., Pearson and Fletcher 2008, Ortega and Pearson 2011). Notably, Ce. stoebe abundance appears to be rebounding in recent years of greater rainfall (Y. K. Ortega and D. E. Pearson, personal observation).

$C y$. achates was not the only biocontrol agent present at our sites. The biocontrol agents Urophora spp. and Larinus spp. were also prevalent. However, the abundance of these agents did not differ across treatments, and therefore did not confound results. Because these agents reduce seed production (e.g., Story et al. 2008), it is possible that they weakened the compensatory recruitment response of $\mathrm{Ce}$. stoebe to adult mortality caused by $C y$. achates. In this context, our results are conservative. Whatever background effects the other agents might have had, the sum of their impacts and $C y$. achates' was insufficient to reduce Ce. stoebe populations or release the native grass. In fact, given that we purged the seed bank and started populations of $\mathrm{Ce}$. stoebe with only adults, what we observed was an overall increase in Ce. stoebe over the three-year experiment due to the proliferation of early age classes.

Each biocontrol introduction offers unique opportunities for studying community ecology. Unfortunately, this fact has been underappreciated, in practice, despite the long history of biocontrol. By examining the $C y$. achates-Ce. stoebe biocontrol system in a community context and under divergent environmental conditions, we illustrate how both biotic and abiotic factors can influence plant-herbivore interactions. Nonetheless, we found that the target weed was remarkably insensitive to short-term drought stress and aggressive herbivore attack because it exhibited strong compensatory recruitment in response to adult mortality. Our results add to a small but growing body of work suggesting that population-level compensation for herbivory may be common among strong invaders. Population-level compensation by plants may be an important mechanism attenuating herbivore-driven and traditional predatordriven cascades.

ACKNOWLEDGMENTS

We appreciate K. McKelvey, R. Callaway, and three anonymous reviewers for helpful comments on the manuscript. Many thanks to L. S. Baggett for statistical advice, to W. Good for advice on $C y$. achates exclusion, and to J. W. Scarborough, J. Amberson, M. Colburn, C. Henderson, T. McGinley, P. Nicol, S. Sears, and A. Zmud for their hard work in the field. This research was supported by the USDA Forest Service Forest Health Protection, Region 1, and Rocky Mountain Research Station. The Missoula Technology Development Center designed and constructed the drought covers.

\section{Literature Cited}

Borer, E. T., E. W. Seabloom, J. B. Shurin, K. E. Anderson, C. A. Blanchette, B. Briotman, S. D. Cooper, and B. S. Halpern. 2005. What determines the strength of a trophic cascade? Ecology 86:528-537.

Callaway, R. M., T. H. DeLuca, and W. M. Belliveau. 1999. Biological-control herbivores increase competitive ability of Centaurea maculosa. Ecology 80:1196-1201.

Carson, W. P., S. M. Hovick, A. J. Baumert, D. E. Bunker, and T. H. Pendergast IV. 2008. Evaluating the post-release efficacy of invasive plant biocontrol by insects: a comprehensive approach. Arthropod-Plant Interactions 2:77-86.

Clark, S. E., R. G. van Driesch, N. Sturdevant, and S. Kegley. 2001. Comparative efficacy of adult and larval sampling for detection of the root-boring insects Agapeta zoegana (Lepidoptera: Cochylidae) and Cyphocleonus achates (Coleoptera: Curculionidae) released for biological control of spotted knapweed. Environmental Entomology 30:589-594.

Corn, J. G., J. M. Story, and L. J. White. 2006. Impacts of the biological control agent Cyphocleonus achates on spotted knapweed, Centaurea maculosa, in experimental plots. Biological Control 37:75-81.

Corn, J. G., J. M. Story, and L. J. White. 2007. Effect of summer drought relief on the impact of the root weevil Cyphocleonus achates on spotted knapweed. Environmental Entomology 36:858-863.

Crawley, M. J. 1989. Insect herbivores and plant population dynamics. Annual Review of Entomology 34:531-564.

Garren, J. M., and S. Y. Strauss. 2009. Population-level compensation by an invasive thistle thwarts biological control from seed predators. Ecological Applications 19:709-721.

Gruner, D. S., J. E. Smith, E. W. Seabloom, S. A. Sandin, J. T. Ngai, H. Hillebrand, W. S. Harpole, J. J. Elser, E. E. Cleland, M. E. S. Bracken, E. T. Borer, and B. M. Bolker. 2008. A cross-system synthesis of consumer and nutrient resource control on producer biomass. Ecology Letters 11:740-755.

Huffaker, C. B., and C. E. Kennett. 1959. A ten-year study of vegetational changes associated with biological control of Klamath weed. Journal of Range Management 12:69-82. 
Jacobs, J. S., S. E. Sing, and J. M. Martin. 2006. Influence of herbivory and competition on invasive weed fitness: observed effects of Cyphocleonus achates (Coleoptera: Curculionidae) and grass-seeding treatments on spotted knapweed performance. Environmental Entomology 35:1590-1596.

Knochel, D. G., N. D. Monson, and T. R. Seastedt. 2010. Additive effects of aboveground and belowground herbivores on the dominance of spotted knapweed (Centaurea stoebe). Oecologia 164:701-712.

Knochel, D. G., and T. R. Seastedt. 2010. Reconciling contradictory findings of herbivore impacts on spotted knapweed (Centaurea stoebe) growth and reproduction. Ecological Applications 20:1903-1912.

MacDougall, A. S., A. Duwyn, and N. T. Jones. 2010. Consumer-based limitations drive oak recruitment failure. Ecology 91:2092-2099.

Maron, J. L., and E. Crone. 2006. Herbivory: effects on plant abundance, distribution and population growth. Proceedings of the Royal Academy B 273:2575-2584.

Maron, J. L., and M. Marler. 2008. Field-based competitive impacts between invaders and natives at varying resource supply. Journal of Ecology 96:1187-1197.

McEvoy, P. B., and E. M. Coombs. 1999. Biological control of plant invaders: regional patterns, field experiments, and structured population models. Ecological Applications 9:387-401.

Mooney, K. A., R. Halitschke, A. Kessler, and A. A. Agrawal. 2010. Evolutionary trade-offs in plants mediate the strength of trophic cascades. Science 327:1642-1644.

Myers, J. H., C. Risley, and R. Eng. 1990. The ability of plants to compensate for insect attack: why biological control of weeds is so difficult. Proceedings of the VII International Symposium on Biological Control of Weed, Rome, Italy.

Ortega, Y. K., and D. E. Pearson. 2005. Weak vs. strong invaders of natural plant communities: assessing invasibility and impact. Ecological Applications 15:651-661.

Ortega, Y. K., and D. E. Pearson. 2011. Long-term effects of weed control with picloram along a gradient of spotted knapweed invasion. Rangeland Ecology and Management 64:67-77.

Pearson, D. E., and R. M. Callaway. 2003. Indirect effects of host-specific biological control agents. Trends in Ecology and Evolution 18:456-461.

Pearson, D. E., and R. M. Callaway. 2006. Biological control agents elevate hantavirus by subsidizing mice. Ecology Letters 9:442-449.

Pearson, D. E., and R. J. Fletcher, Jr. 2008. Mitigating exotic impacts: restoring deer mouse populations elevated by an exotic food subsidy. Ecological Applications 18:1489-1500.

Polis, G. A., A. L. W. Sears, G. R. Huxel, D. R. Strong, and J. Maron. 2000. When is a trophic cascade a trophic cascade? Trends in Ecology and Evolution 15:473-475.
Power, M. E., D. Tilman, J. A. Estes, B. A. Menge, W. J. Bond, L. S. Mills, G. Daily, J. C. Castilla, J. Lubchenco, and R. T. Paine. 1996. Challenges in the quest for keystones. BioScience 46:609-620.

Pringle, R. M., T. P. Young, D. I. Rubenstein, and D. J. McCauley. 2007. Herbivore-initiated interaction cascades and their modulation by productivity in an African savanna. Proceedings of the National Academy of Sciences USA 104:193-197.

SAS Institute. 2009. SAS/STAT user's guide, version 9.2. SAS Institute, Cary, North Carolina, USA.

Seastedt, T. R., D. G. Knochel, M. Garmoe, and S. A. Shosky. 2007. Interactions and effects of multiple biological control insects on diffuse and spotted knapweed in the Front Range of Colorado. Biological Control 42:345-354.

Shea, K., D. Kelly, A. W. Sheppard, and T. L. Woodburn. 2005. Context-dependent biological control of an invasive thistle. Ecology 86:3174-3181.

Sheppard, A. W., M. J. Smyth, and A. Swirepik. 2001. The impact of a root-crown weevil and pasture competition on the winter annual Echium plantagineum. Journal of Applied Ecology 38:291-300.

Story, J. M., W. Callan, J. G. Corn, and L. J. White. 2006. Decline of spotted knapweed density at two sites in western Montana with large populations of the introduced root weevil, Cyphocleonus achates (Fahraeus). Biological Control 38:227-232.

Story, J. M., L. Smith, J. G. Corn, and L. J. White. 2008. Influence of seed head-attacking biological control agents on spotted knapweed reproductive potential in western Montana over a 30-year period. Environmental Entomology 37:510-519.

Story, J. M., L. J. White, and W. R. Good. 1996. Propagation of Cyphocleonus achates (Fahraeus) (Coleoptera: Curculionidae) for biological control of spotted knapweed: procedures and cost. Biological Control 7:167-171.

Swope, S. M., and I. M. Parker. 2010. Widespread seed limitation affects plant density but not population trajectory in the invasive plant Centaurea solstitialis. Oecologia 164:117-128.

Syrett, P., D. T. Briese, and J. H. Hoffmann. 2000. Success in biological control of terrestrial weeds by arthropods. Pages 189-230 in G. Gurr and S. Wratten, editors. Biological control: measures of success. Kluwer Academic, Dordrecht, The Netherlands.

Thelen, G. C., J. M. Vivanco, B. A. Newingham, W. Good, H. P. Bais, P. Landres, A. J. Caesar, and R. M. Callaway. 2005. Insect herbivory stimulates allelopathic exudation by an invasive plant and the suppression of natives. Ecology Letters 8:209-217.

van Driesche, R. G., and T. S. Bellows, Jr. 1996. Biological control. Chapman and Hall, New York, New York, USA.

\section{Supplemental Material}

\section{Appendix A}

Table with results from mixed model analysis of performance measures for the exotic forb, Centaurea stoebe (Ecological Archives E093-069-A1).

\section{Appendix B}

Table with results from mixed model analysis of population-level measures for the exotic forb, Centaurea stoebe (Ecological Archives E093-069-A2).

\section{Appendix C}

Table with results from mixed model analysis of performance and population-level measures for the native grass, Pseudoroegneria spicata (Ecological Archives E093-069-A3). 